\title{
Expression of AMP-activated protein kinase/ten-eleven translocation 2 and their clinical relevance in colorectal cancer
}

\author{
DONG HYUN KANG ${ }^{1 *}$, DONG JUN JEONG ${ }^{2,3^{*}}$, TAE SUNG AHN ${ }^{1}$, HYUN YONG LEE $^{1}$, HAN JO KIM ${ }^{4}$, \\ SANG BYUNG BAE ${ }^{4}$, HYEONG JOO KIM ${ }^{2}$, MOON SOO LEE ${ }^{6}$, HYOG YOUNG KWON ${ }^{5}$ and MOO-JUN BAEK ${ }^{1}$ \\ ${ }^{1}$ Division of Colon and Rectal Surgery, Department of Surgery, ${ }^{2}$ Soonchunhyang Medical Science Research Institute; \\ Departments of ${ }^{3}$ Pathology and ${ }^{4}$ Oncology, College of Medicine, Soonchunhyang University Cheonan Hospital; \\ ${ }^{5}$ Soonchunhyang Institute of Medi-bio Science (SIMS), Soonchunhyang University; ${ }^{6}$ Division of Gastrointestinal Surgery, \\ Department of Surgery, College of Medicine, Soonchunhyang University Cheonan Hospital, Cheonan, \\ Chungcheongnam-do 31151, Republic of Korea
}

Received August 22, 2019; Accepted November 26, 2020

DOI: $10.3892 / \mathrm{ol} .2021 .12425$

\begin{abstract}
Inactivation of the ten-eleven translocation (TET) family members and catalyzation of 5-methylcytosine (5-mC) into 5-hydroxymethylcytosine $(5-\mathrm{hmC})$ is associated with cancer initiation and progression. AMP-activated protein kinase (AMPK) is an enzyme that stabilizes TET2; however, the clinical relevance of AMPK and TET2 expression levels is currently unclear. Therefore, the present study aimed to investigate the clinical implications of AMPK/TET2 expression levels in colorectal cancer (CRC). Immunohistochemistry was used to retrospectively examine the expression levels of AMPK and TET2 in paraffin-embedded specimens obtained from 343 patients with CRC. The results demonstrated that AMPK and TET2 were highly expressed in CRC samples. No significant association was observed between the expression levels of TET2 and patient clinicopathological characteristics (age, tumor location, lymphatic, vascular and perineural invasion, Tumor-Node-Metastasis stages and differentiation); however, patients with low expression levels of TET2 more frequently presented with distant metastasis. By contrast, the expression levels of AMPK were significantly associated with lymph node and distant metastases. The survival analysis results revealed that high expression levels of TET2 were an independent predictor of favorable prognosis compared with low TET2 levels. However, no significant differences in overall survival were observed between patients with high and
\end{abstract}

Correspondence to: Dr Moo-Jun Baek, Division of Colon and Rectal Surgery, Department of Surgery, College of Medicine, Soonchunhyang University Cheonan Hospital, 31 Suncheonhyang 6-gil, Dongnam, Cheonan, Chungcheongnam-do 31151, Republic of Korea

E-mail: ssurge@schmc.ac.kr

${ }^{*}$ Contributed equally

Key words: AMP-activated protein kinase, ten-eleven translocation 2 , colorectal cancer, biomarker, diabetes mellitus low expression levels of AMPK. These results described the clinical significance of AMPK/TET2 in CRC. The results of the multivariate analysis demonstrated that high expression levels of TET2 were a predictor of a favorable prognosis, whereas AMPK was not a significant factor for determining patient prognosis; therefore, further functional analysis of AMPK/TET2 expression in CRC is needed.

\section{Introduction}

Colorectal cancer (CRC) was the third most common cancer among men and women in 2020 South Korea, and it is one of the deadliest types of cancer worldwide $(1,2)$. In the United States, there are 147,950 new cases and 53,200 deaths annually associated with CRC (3). The development of CRC is very complex and is associated with genetic and epigenetic alterations (4). In addition, the causes of CRC can be heterogenic, and there are multiple underlying molecular pathways, such as the suppressor pathway, the serrated pathway and the Lynch syndrome (5). These various molecular pathways result in difficulties in CRC treatment; therefore it is important identify effective biomarkers and efficient methods to predict the prognosis of CRC.

Methylation results in the silencing of cancer suppressor or base repair genes and occurs through the binding of methylated complexes (6). Oxidation of 5-methylcytosine (5-mC) into 5-hydroxymethylcytosine (5-hmC), as well as 5-hmC-induced 5-formylcytosine (5-fC) and 5-carboxylcytosine (5-caC) are epigenetic modifications $(7,8)$. 5-mC can be actively removed by oxidative demethylation by the ten-eleven translocation enzyme family (TET1, TET2, and TET3) or by passive demethylation through replication (9). 5-hmC is a hallmark of DNA demethylation, and its levels have been reported to be downregulated in various types of cancer, including colon cancer $(10,11)$. The loss of $5-\mathrm{hmC}$ is caused by the inhibition of TET enzyme activity along with an increase of the onco-metabolite 2-hydroxyglutarate due to a mutation in the isocitrate dehydrogenases (IDH1/2) and by a TET mutation, reducing the TET stability (10).

AMP-activated protein kinase (AMPK) is a member of the serine/threonine kinase family and forms a heterotrimeric 


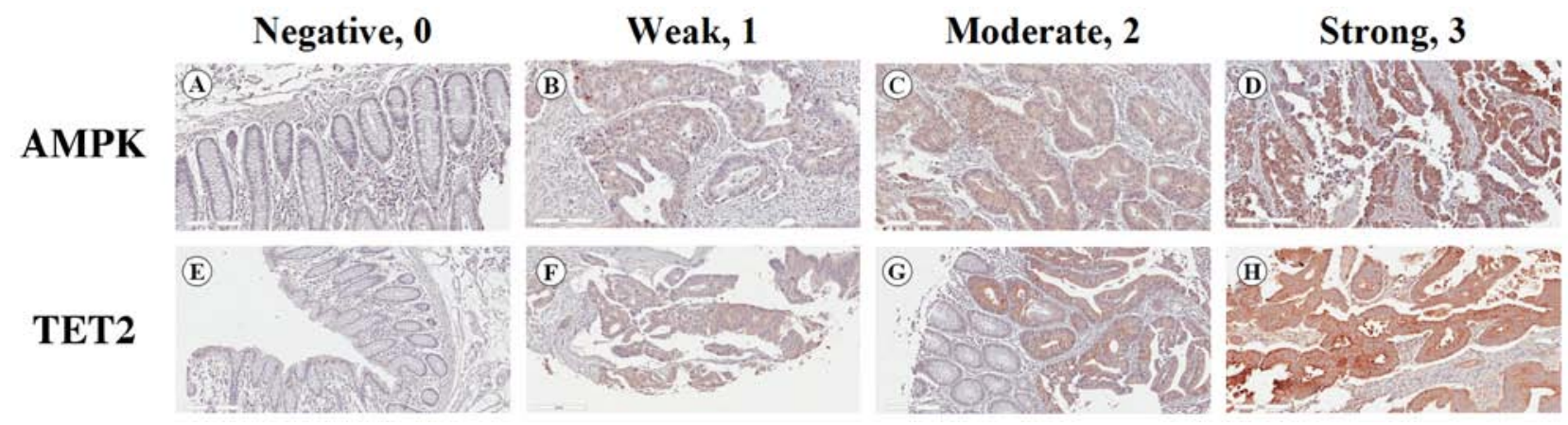

Figure 1. Immunohistochemical staining of the expression levels of AMPK and TET2 in CRC specimens. (A-D) AMPK and (F-H) TET2 proteins were mainly detected in the cytoplasm and membrane of CRC cells. Representative staining patterns of CRC with (A and E) negative, (B and F) weak, (C and G) moderate and (D and H) strong staining intensity. Magnification, x200. CRC, colorectal cancer; AMPK, AMP-activated protein kinase; TET2, ten-eleven translocation 2.

complex with one catalytic subunit $(\alpha 1$ and $\alpha 2)$, and two regulatory $\beta$ ( $\beta 1$ or $\beta 2)$ and $\gamma(\gamma 1, \gamma 2$ or $\gamma 3)$ subunits (12). AMPK is a direct intracellular sensor that responds to ATP depletion and restores energy homeostasis by inhibiting ATP-consuming fatty acid and cholesterol synthesis and promoting the generation of ATP (13). The activation of AMPK serves an important role in the survival of tumor cells under stressful conditions such as energy stress, hypoxia and hypoglycemia, which are common in the tumor microenvironment $(13,14)$. In addition, previous studies have demonstrated that the metabolic state regulates the epigenome directly through the AMPK-dependent phosphorylation of the epigenetic modifying enzyme $(14,15)$. Wu et al (15) have reported that AMPK increases the activity of TET2 and stabilizes it by phosphorylation in normal compared with high glucose conditions, which converts $5-\mathrm{mC}$ bases to 5 -hmC, thus altering the epigenome.

However, it is still unclear how AMPK/TET2 protein expression is affected in patients with CRC. The aim of the present study was to investigate the association between AMPK/TET2 expression levels and other clinicopathological factors in patients with $\mathrm{CRC}$ and to investigate its role as a prognostic factor.

\section{Materials and methods}

Patients and samples. Between January 2010 and December 2014, 360 patients who were diagnosed with CRC underwent surgical resection at the Department of Surgery, Soonchunhyang University Cheonan Hospital (Cheonan, South Korea) were included in the present study. Only patients with stage I-IV $\mathrm{CRC}$ were included. The specimens used in the study were fixed in $10 \%$ formalin for $24-48 \mathrm{~h}$ at room temperature, embedded in paraffin and stored at the Department of Pathology. The exclusion criteria were as follows: i) Patients who underwent preoperative chemotherapy and radiotherapy; ii) those who died within 30 days of the surgery; iii) those under 18 years old; iv) those with Lynch syndrome or familial adenomatous polyposis. Subsequently, a total of 343 patients were enrolled in the present study. The patient clinicopathological data were retrospectively collected through medical records. For the survival analysis, the patients' medical records were assessed, or they were contacted by a direct telephone call; the duration of disease-free survival (DFS) was analyzed by imaging (CT or MRI) and an endoscopic follow-up. The median follow-up time for all patients was 2.4 years (range, $0-7.5$ years); 17 patients were lost to the follow-up. Tumor stage was defined according to the Tumor-Node-Metastasis (TNM) classification of the American Joint Committee on International Union against Cancer 7th Edition (16). This study was approved by the Institutional Review Board of the Soonchunhyang University Cheonan Hospital (approval no. SCHCA 2019-08-018).

Immunohistochemical staining of TET2 and AMPK. Immunohistochemical staining of the CRC tissues was performed using a tissue microarray (TMA) block of 343 patient tissues. The tissue core punched by a $2-\mathrm{mm}$ puncher (Unitech Korea Co., Ltd.) was embedded in a recipient paraffin block (Unitech Korea Co., Ltd.). The TMA blocks were cut into 4- $\mu \mathrm{m}$ sections, dewaxed in xylene and rehydrated through a gradient concentration of ethanol $(100,95,90,80$ and $70 \%)$ for 5 min per concentration. Subsequently, the blocks were incubated in $0.01 \mathrm{M}$ citrate buffer $(\mathrm{pH} 6.0)$ at $95^{\circ} \mathrm{C}$ for $30 \mathrm{~min}$ in a microwave. Endogenous peroxidase activity was inactivated using $0.3 \% \mathrm{H}_{2} \mathrm{O}_{2}$ for $1 \mathrm{~h}$ at room temperature. The sections were subsequently incubated with antibodies against TET2 (1:100; cat. no. ab245287; Abcam) and AMPK (1:100; cat. no. GTX52341; GeneTex, Inc.) overnight at $4^{\circ} \mathrm{C}$, followed by incubation with an anti-rabbit EnVision secondary antibody (cat. no. K4002; Dako; Agilent Technologies, Inc.) for $1 \mathrm{~h}$ at $37^{\circ} \mathrm{C}$. For visualization, the sections were treated with $\mu 1$ 3,3'-diaminobenzidine solution (Dako; Agilent Technologies, Inc.) and counterstained with Harris' hematoxylin (EMD Millipore). The sections were mounted using Canada Balsam (Sigma-Aldrich; Merck KGaA).

Semiquantitative analysis of AMPK and TET2. Protein expression was analyzed by two independent groups of researchers who were blinded to patient clinical data; they reached consensus scores for each specimen by evaluating the percentage of positive cells and the intensity of staining. The proportion of stained cells was classified on a scale of 0 to 3 as follows: $0,0 \% ; 1,1-33 \% ; 2,34-66 \%$; and $3,67-100 \%$. The staining intensity was classified into four grades: 0 , negative; 1, weak; 2, moderate; and 3, strong (Fig. 1). The two scores were multiplied to obtain final protein expression scores, which were classified as follows: 0 , negative; 1-3, weak; 4-6, moderate; and 7-9, strong. 'Negative' and 'weak' denoted low expression, whereas 'moderate' and 'strong' denoted high expression. 
Statistical analysis. Statistical analyses were performed using PASW Statistics v.18.0 (SPSS, Inc.). The $\chi^{2}$ or Fisher's exact test were used to analyze the associations between categorical clinicopathological variables and the expression levels of AMPK and TET2. Phi correlation analysis was used to determine the relationship between AMPK and TET2 expression levels. Survival curves for overall survival (OS) and DFS rates were calculated using the Kaplan-Meier method and compared by the log-rank test, and the Bonferroni correction was used to adjust for multiple comparisons. Univariate and multivariate analyses of patient prognosis were performed using Cox proportional hazards modeling. $\mathrm{P}<0.05$ was considered to indicate a statistically significant difference.

\section{Results}

Baseline clinicopathological data. The baseline clinicopathological characteristics of the patients are presented in Table I. Among them, 145 were female and 198 were male. The median age was 64.2 (range, 29-89) years, male patients $(57.7 \%$ ) were more common than female patients, and patients with diabetes comprised $19.8 \%$ of the study cohort. The predominant primary tumor location was on the left side (66.2\%). The percentages of patients at each pathological stage were $16.6 \%$ at stage I, $44.3 \%$ at stage II, $32.9 \%$ at stage III and $6.1 \%$ at stage IV. In addition, there were more patients without lymph node metastasis compared with those with lymph node metastasis, and $7 \%$ of patients presented with distant metastasis.

Expression of AMPK and TET2 in CRC tissue. Expression of AMPK and TET2 was assessed in tissues from 343 patients with CRC by immunohistochemical staining. AMPK and TET2 were stained in the cytoplasm and membrane of tumor cells and confirmed by microscopy. According to the semiquantitative analysis, the percentages of patients with high expression levels of AMPK and TET2 were 25.9 and 27.1\%, respectively (Table I).

Associations between the expression levels of AMPK and TET2 and the clinicopathological characteristics of patients with $C R C$. Age, sex, diabetes mellitus status, fasting glucose and glycated hemoglobin (HbAlc) levels, tumor size, tumor location, vascular, lymphatic and perineural invasion, pTNM status, tumor differentiation and overall stage were included to evaluate the clinical relevance of AMPK and TET2 expression levels. Patients with high expression levels of AMPK more frequently presented with lymphatic invasion $(\mathrm{P}<0.001)$, lymph node metastasis $(\mathrm{P}<0.001)$, distant metastasis $(\mathrm{P}=0.019)$ and an advanced stage $(\mathrm{P}<0.001)$ compared with those in the low AMPK expression group. However, distant metastasis was more common among patients with low expression levels of TET2 compared with those in the high TET2 expression group ( $\mathrm{P}=0.017)$ (Table II). No associations were observed between the expression levels of TET2 and the following clinicopathological variables: Age, sex, diabetes mellitus status, fasting glucose or HbAlc levels, tumor size, location, vascular or lymphatic invasion and overall stage.

Association between the expression levels of AMPK and TET. The expression levels of AMPK and TET2 were both low in
Table I. Clinicopathological characteristics of patients with colorectal cancer.

\begin{tabular}{|c|c|}
\hline Characteristics & Frequency, n $(\%$ \\
\hline Total & $343(100 \%)$ \\
\hline Age, mean (range) years & $64(29-89)$ \\
\hline \multicolumn{2}{|l|}{ Sex } \\
\hline Male & $198(57.7 \%)$ \\
\hline Female & $145(42.3 \%)$ \\
\hline \multicolumn{2}{|l|}{ Diabetes mellitus } \\
\hline Yes & $68(19.8 \%)$ \\
\hline No & $275(80.2 \%)$ \\
\hline \multicolumn{2}{|l|}{ pT stage } \\
\hline $\mathrm{T} 1$ & $26(7.6 \%)$ \\
\hline $\mathrm{T} 2$ & $45(13.1 \%)$ \\
\hline $\mathrm{T} 3$ & $216(63.0 \%)$ \\
\hline $\mathrm{T} 4$ & $56(16.3 \%)$ \\
\hline \multicolumn{2}{|l|}{ pN stage } \\
\hline No & $218(63.5 \%)$ \\
\hline $\mathrm{N} 1$ & $81(23.6 \%)$ \\
\hline $\mathrm{N} 2$ & $44(12.9 \%)$ \\
\hline \multicolumn{2}{|l|}{ pM stage } \\
\hline M0 & $322(93.8 \%)$ \\
\hline M1 & $21(6.2 \%)$ \\
\hline \multicolumn{2}{|l|}{ Tumor location } \\
\hline Right & $116(33.8 \%)$ \\
\hline Left & $227(66.2 \%)$ \\
\hline \multicolumn{2}{|l|}{ Tumor size } \\
\hline$<5 \mathrm{~cm}$ & $226(65.9 \%)$ \\
\hline$\geq 5 \mathrm{~cm}$ & $117(34.1 \%)$ \\
\hline \multicolumn{2}{|l|}{ Vascular invasion } \\
\hline Yes & $54(15.7 \%)$ \\
\hline No & $289(84.3 \%)$ \\
\hline \multicolumn{2}{|l|}{ Lymphatic invasion } \\
\hline Yes & $96(28.0 \%)$ \\
\hline No & $247(72.0 \%)$ \\
\hline \multicolumn{2}{|l|}{ Perineural invasion } \\
\hline Yes & $116(33.8 \%)$ \\
\hline No & $227(66.2 \%)$ \\
\hline \multicolumn{2}{|l|}{ Differentiation } \\
\hline Well/moderately differentiated & $322(93.9 \%)$ \\
\hline Poorly differentiated & $21(6.1 \%)$ \\
\hline \multicolumn{2}{|l|}{ AMPK levels } \\
\hline High & $89(25.9 \%)$ \\
\hline Low & $254(74.1 \%)$ \\
\hline \multicolumn{2}{|l|}{ TET2 levels } \\
\hline High & $93(27.1 \%)$ \\
\hline Low & $250(72.9 \%)$ \\
\hline
\end{tabular}

T, tumor; N, node; M, metastasis; AMPK, AMP-activated protein kinase; TET2, ten eleven translocation 2.

$194(56.5 \%)$ cases, and both were high in 33 (9.6\%) cases. In addition, high expression levels of TET2 were more frequently 
Table II. Associations between AMPK and TET2 levels and the clinicopathological factors of patients with colorectal cancer.

\begin{tabular}{|c|c|c|c|c|c|c|c|}
\hline \multirow[b]{2}{*}{ Characteristics } & \multirow[b]{2}{*}{$\mathrm{n}(\%)$} & \multicolumn{3}{|c|}{ AMPK levels, n (\%) } & \multicolumn{3}{|c|}{ TET2 levels, n (\%) } \\
\hline & & Low $(\%)$ & High $(\%)$ & $\mathrm{P}$-value & Low $(\%)$ & High (\%) & P-value \\
\hline Total & $343(100)$ & $254(74.1)$ & $89(25.9)$ & & $250(72.9)$ & $93(27.1)$ & \\
\hline Age, years & & & & 0.729 & & & 0.459 \\
\hline$<60$ & $122(35.6)$ & $89(35.0)$ & $33(37.1)$ & & $86(34.4)$ & $36(38.7)$ & \\
\hline$\geq 60$ & $221(64.4)$ & $165(65.0)$ & $56(62.9)$ & & $164(65.6)$ & $57(61.3)$ & \\
\hline Sex & & & & 0.180 & & & 0.746 \\
\hline Male & $198(57.7)$ & $152(59.8)$ & $46(51.7)$ & & $143(57.2)$ & $55(59.1)$ & \\
\hline Female & $145(42.3)$ & $102(40.2)$ & $43(48.3)$ & & $107(42.8)$ & $38(40.9)$ & \\
\hline Diabetes mellitus & & & & 0.611 & & & 0.894 \\
\hline Yes & $68(19.8)$ & $52(20.5)$ & $16(18.0)$ & & $200(80.0)$ & $75(80.6)$ & \\
\hline No & $275(80.2)$ & $202(79.5)$ & $73(82.0)$ & & $50(20.0)$ & $18(19.4)$ & \\
\hline Fasting glucose level, mg/dl & & & & 0.406 & & & 0.713 \\
\hline$>126$ & $114(32.7)$ & $84(33.1)$ & $30(33.7)$ & & $82(32.8)$ & $32(34.4)$ & \\
\hline $100-125$ & $117(34.1)$ & $82(32.3)$ & $35(39.3)$ & & $85(34.0)$ & $32(34.4)$ & \\
\hline$<100$ & $112(33.2)$ & $88(34.6)$ & $24(27.0)$ & & $83(33.2)$ & $29(31.2)$ & \\
\hline Glycated hemoglobin, $\%$ & & & & 0.524 & & & 0.175 \\
\hline$<6.5$ & $126(68.9)$ & $87(67.4)$ & $39(72.2)$ & & $100(71.4)$ & $26(60.5)$ & \\
\hline$\geq 6.5$ & $57(31.1)$ & $42(32.6)$ & $15(27.8)$ & & $40(28.6)$ & $17(39.5)$ & \\
\hline Tumor size, $\mathrm{cm}$ & & & & 0.257 & & & 0.340 \\
\hline$<5$ & $226(65.9)$ & $163(64.2)$ & $63(70.8)$ & & $161(64.4)$ & $65(69.9)$ & \\
\hline$\geq 5$ & $117(34.1)$ & $91(35.8)$ & $26(29.2)$ & & $89(35.6)$ & $28(30.1)$ & \\
\hline Tumor location & & & & 0.815 & & & 0.154 \\
\hline Right & $116(33.8)$ & $85(33.5)$ & $31(34.8)$ & & 79 (31.6) & $37(39.8)$ & \\
\hline Left & $227(66.2)$ & $169(66.5)$ & $58(65.2)$ & & $171(68.4)$ & $56(60.2)$ & \\
\hline Vascular invasion & & & & 0.043 & & & 0.378 \\
\hline Yes & $54(15.7)$ & $34(13.4)$ & $20(22.5)$ & & $42(16.8)$ & $12(12.9)$ & \\
\hline No & $289(84.3)$ & $220(86.6)$ & $69(77.5)$ & & $208(83.2)$ & $81(87.1)$ & \\
\hline Lymphatic invasion & & & & $<0.001$ & & & 0.994 \\
\hline Yes & $96(28.0)$ & $56(22.0)$ & $40(44.9)$ & & $70(28.0)$ & $67(72.0)$ & \\
\hline No & $247(72.0)$ & $198(78.0)$ & $49(55.1)$ & & $180(72.0)$ & $26(28.0)$ & \\
\hline Perineural invasion & & & & 0.310 & & & 0.375 \\
\hline Yes & $116(33.8)$ & $82(32.3)$ & $34(38.2)$ & & $88(35.2)$ & $28(30.1)$ & \\
\hline No & $227(66.2)$ & $172(67.7)$ & $55(61.8)$ & & $162(64.8)$ & $65(69.9)$ & \\
\hline pT stage & & & & 0.766 & & & 0.155 \\
\hline $\mathrm{T} 1$ & $26(7.6)$ & $20 \quad(7.9)$ & $6(6.7)$ & & $22(8.8)$ & $4(4.3)$ & \\
\hline $\mathrm{T} 2$ & $45(13.1)$ & $32(12.6)$ & $13(14.6)$ & & $29(11.6)$ & $16(17.2)$ & \\
\hline $\mathrm{T} 3$ & $216(63.0)$ & $163(64.2)$ & $53(59.6)$ & & $162(64.8)$ & $54(58.1)$ & \\
\hline $\mathrm{T} 4$ & $56(16.3)$ & $39(15.4)$ & $17(19.1)$ & & $37(14.8)$ & $19(20.4)$ & \\
\hline pN stage & & & & $<0.001$ & & & 0.978 \\
\hline NO & $218(63.6)$ & $178(70.1)$ & $40(44.9)$ & & $159(63.6)$ & $59(63.4)$ & \\
\hline $\mathrm{N} 1+\mathrm{N} 2$ & $125(36.4)$ & $76(29.9)$ & $49(55.1)$ & & $91(36.4)$ & $34(36.6)$ & \\
\hline Distant metastasis & & & & 0.019 & & & 0.017 \\
\hline Absent & $322(93.9)$ & $243(95.7)$ & $79(88.8)$ & & $230(92.0)$ & $92(98.9)$ & \\
\hline Present & $21 \quad(6.1)$ & 11 (4.3) & $10(11.2)$ & & $20(8.0)$ & 1 (1.1) & \\
\hline Differentiation & & & & 0.457 & & & 0.877 \\
\hline Well/moderately differentiated & $322(93.9)$ & $237(93.3)$ & $85(95.5)$ & & $235(94.0)$ & $87(93.5)$ & \\
\hline Poorly differentiated & $21 \quad(6.1)$ & $17(6.7)$ & $4(4.5)$ & & $15(6.0)$ & $6(6.5)$ & \\
\hline Overall stage & & & & $<0.001$ & & & 0.615 \\
\hline I-II & $199(58.0)$ & $164(64.6)$ & $35(39.3)$ & & $143(57.2)$ & $56(60.2)$ & \\
\hline III-IV & $144(42.0)$ & $90(35.4)$ & $54(60.7)$ & & $107(42.8)$ & $37(39.8)$ & \\
\hline
\end{tabular}

T, tumor; N, node; M, metastasis; AMPK, AMP-activated protein kinase; TET2, ten eleven translocation 2. 
Table III. Correlation between the expression levels of AMPK and TET2.

\begin{tabular}{|c|c|c|c|c|}
\hline \multirow[b]{2}{*}{ Protein markers } & \multirow[b]{2}{*}{$\mathrm{n},(\%)$} & \multicolumn{3}{|c|}{ TET2, n (\%) } \\
\hline & & Low (\%) & High (\%) & P-value \\
\hline AMPK, n (\%) & & & & $0.014^{\mathrm{a}}$ \\
\hline Low & $254(74.1 \%)$ & $194(77.6)$ & $60(64.5)$ & \\
\hline High & $89(25.9 \%)$ & $56(22.4)$ & $33(35.5)$ & \\
\hline Phi coefficient & 0.341 & & & $0.014^{\mathrm{b}}$ \\
\hline
\end{tabular}

Table IV. Univariate and multivariate analysis using Cox's proportional hazard regression model for disease-free survival.

\begin{tabular}{|c|c|c|c|c|}
\hline \multirow[b]{2}{*}{ Clinicopathological parameters } & \multicolumn{2}{|c|}{ Univariate analysis } & \multicolumn{2}{|c|}{ Multivariate analysis } \\
\hline & HR $(95 \% \mathrm{CI})$ & P-value & HR $(95 \% \mathrm{CI})$ & P-value \\
\hline Age ( $<60$ vs. $\geq 60$ years $)$ & $1.332(0.861-2.060)$ & 0.198 & & \\
\hline Sex (male vs. female) & $1.178(0.782-1.775)$ & 0.433 & & \\
\hline DM (yes vs. no) & $0.794(0.457-1.381)$ & 0.415 & & \\
\hline Tumor location (right vs. left) & $0.976(0.634-1.504)$ & 0.914 & & \\
\hline Vascular invasion (yes vs. no) & $2.020(1.241-3.288)$ & 0.005 & $1.629(0.951-2.791)$ & 0.076 \\
\hline Lymphatic invasion (yes vs. no) & $2.075(1.364-3.156)$ & 0.001 & $0.643(0.386-1.071)$ & 0.090 \\
\hline Perineural invasion (yes vs. no) & $2.723(1.807-4.105)$ & $<0.001$ & $1.812(1.153-2.847)$ & 0.010 \\
\hline AJCC stage (I, II vs. III, IV) & $4.588(2.923-7.200)$ & $<0.001$ & $4.515(2.706-7.532)$ & $<0.001$ \\
\hline TET2 (high vs. low) & $0.582(0.348-0.975)$ & 0.040 & $0.568(0.339-0.952)$ & 0.032 \\
\hline AMPK (high vs. low) & $1.586(1.029-2.444)$ & 0.037 & $1.359(0.865-2.137)$ & 0.183 \\
\hline AMPK high/TET2 low vs. AMPK low/TET2 high & $3.569(1.579-8.066)$ & 0.002 & $2.840(1.241-6.498)$ & 0.013 \\
\hline
\end{tabular}

HR, hazard ratio; AMPK, AMP-activated protein kinase; TET2, ten eleven translocation 2; DM, diabetes mellitus; AJCC, American Joint Committee on Cancer.

observed in patients with high AMPK expression levels $(\mathrm{P}=0.014$; Table III). There was also a statistically significant correlation between AMPK and TET2 expression levels $(\mathrm{P}=0.014)$.

Univariate and multivariate survival analysis. The Cox proportional hazard model was used to determine whether the independent factors affected the OS and DFS rates in patients with CRC. Regarding the DFS rates, vascular invasion (HR, 2.020; 95\% CI, 1.241-3.288; $\mathrm{P}=0.005)$, lymphatic invasion (HR, 2.075; 95\% CI, 1.364-3.156; $\mathrm{P}=0.001)$, perineural invasion (HR, 2.723; 95\% CI, 1.807-4.105; P<0.001), AJCC stage (HR, 4.588; 95\% CI, 2.923-7.200; $\mathrm{P}<0.001$ ), high expression levels of TET2 (HR, 0.582; 95\% CI, 0.348-0.975; $\mathrm{P}=0.040)$ and AMPK (HR, 1.586; 95\% CI, 1.029-2.444; $\mathrm{P}=0.037$ ) were significant prognostic factors according to the results of the univariate analysis. The multivariate analysis demonstrated that perineural invasion (HR, 1.812; 95\% CI, 1.153-2.847; $\mathrm{P}=0.010)$ and AJCC stage (HR, 4.515; 95\% CI, 2.706-7.532; $\mathrm{P}<0.001)$ were independent prognostic factors associated with DFS. High expression levels of TET2 (HR, 0.568; 95\% CI, 0.339-0.952; $\mathrm{P}=0.032$ ) was identified to be an independent predictor of a favorable prognosis; however, the expression levels of AMPK (HR, 1.359; 95\% CI, 0.865-2.137; $\mathrm{P}=0.183$ ) were not significantly associated with DFS in the multivariate analysis (Table IV).

In the OS rate univariate analysis, vascular (HR, 2.467; 95\% CI, 1.416-4.299; $\mathrm{P}=0.001)$, lymphatic (HR, 2.976; 95\% CI, 1.822-4.862; $\mathrm{P}<0.001)$ and perineural (HR, 2.869; 95\% CI, 1.754-4.692; $\mathrm{P}<0.001)$ invasion, AJCC stage (HR, 7.681; 95\% CI, 4.097-14.401; $\mathrm{P}<0.001$ ), and high expression levels of TET2 (HR, 0.369; 95\% CI, 0.182-0.748; $\mathrm{P}=0.006)$ and AMPK (HR, 1.761; 95\% CI, 1.061-2.921; $\mathrm{P}=0.028)$ were significant prognostic factors. By contrast, the results of the multivariate analysis demonstrated that the expression levels of TET2 (HR, 0.369; 95\% CI, 0.182-0.748; P=0.006) were an independent predictor of a favorable prognosis; however, the expression levels of AMPK were not significantly associated with OS (Table V).

The results of Kaplan-Meier analysis with the log-rank test demonstrated that the 5-year DFS rate of patients with high expression levels of TET2 was significantly higher compared with that of patients with low TET2 levels $(\mathrm{P}=0.037)$. However, patients with high expression levels of AMPK exhibited lower survival rates compared with those in the low AMPK expression group ( $\mathrm{P}=0.035$; Fig. 2). The 5-year OS rate of patients with 
Table V. Univariate and multivariate analysis using Cox's proportional hazard regression model for overall survival.

\begin{tabular}{|c|c|c|c|c|}
\hline \multirow[b]{2}{*}{ Clinicopathological parameters } & \multicolumn{2}{|c|}{ Univariate analysis } & \multicolumn{2}{|c|}{ Multivariate analysis } \\
\hline & HR $(95 \%$ CI) & P-value & HR $(95 \% \mathrm{CI})$ & P-value \\
\hline Age ( $<60$ vs. $\geq 60$ years) & $1.422(0.843-2.397)$ & 0.187 & & \\
\hline Sex (male vs. female) & $1.332(0.816-2.175)$ & 1.332 & & \\
\hline Diabetes mellitus (yes vs. no) & $0.945(0.504-1.771)$ & 0.860 & & \\
\hline Tumor location (right vs. left) & $0.853(0.512-1.421)$ & 0.540 & & \\
\hline Vascular invasion (yes vs. no) & $2.467(1.416-4.299)$ & 0.001 & $2.029(1.156-3.562)$ & 0.014 \\
\hline Lymphatic invasion (yes vs. no) & $2.976(1.822-4.862)$ & $<0.001$ & $0.849(0.476-1.515)$ & 0.580 \\
\hline Perineural invasion (yes vs. no) & $2.869(1.754-4.692)$ & $<0.001$ & $1.496(0.863-2.594)$ & 0.151 \\
\hline AJCC stage (I, II vs. III, IV) & $7.681(4.097-14.401)$ & $<0.001$ & $7.211(3.811-13.641)$ & $<0.001$ \\
\hline TET2 (high vs. low) & $0.369(0.182-0.748)$ & 0.006 & $0.369(0.182-0.748)$ & 0.006 \\
\hline AMPK (high vs. low) & $1.761(1.061-2.921)$ & 0.028 & $1.288(0.763-2.176)$ & 0.344 \\
\hline AMPK high/TET2 low vs. AMPK low/TET2 high & $5.449(2.043-14.533)$ & 0.001 & $3.304(1.232-8.861)$ & 0.018 \\
\hline
\end{tabular}

HR, hazard ratio; AMPK, AMP-activated protein kinase; TET2, ten eleven translocation 2; AJCC, American Joint Committee on Cancer.
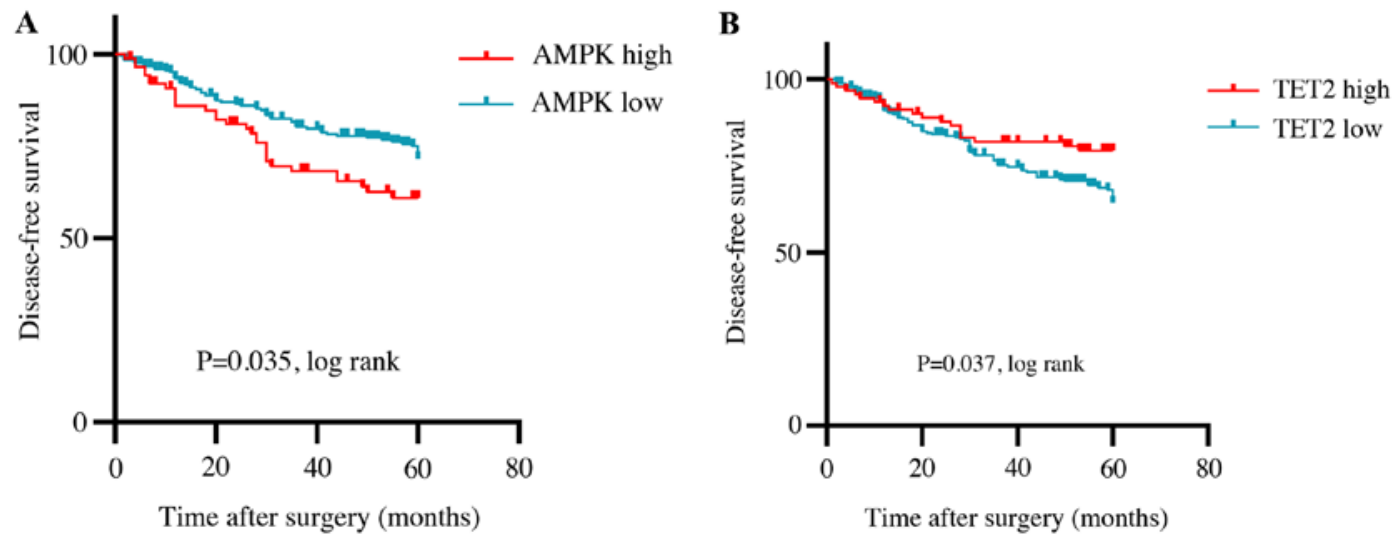

Figure 2. Kaplan-Meier survival curves of disease-free survival. (A and B) Survival analysis based on (A) AMPK and (B) TET2 expression levels. AMPK, AMP-activated protein kinase; TET2, ten-eleven translocation 2.
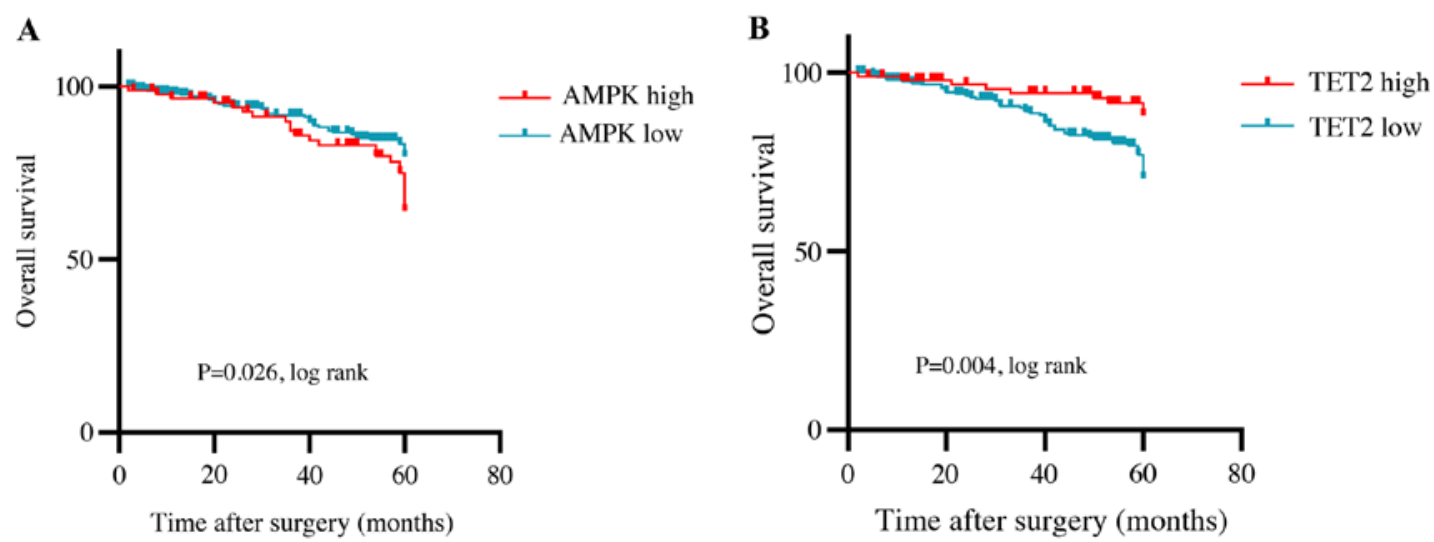

Figure 3. Kaplan-Meier survival curves of overall survival. (A and B) Survival analysis based on (A) AMPK and (B) TET2 expression levels. AMPK, AMP-activated protein kinase; TET2, ten-eleven translocation 2.

high expression levels of TET2 was higher compared with that of patients in the low TET2 expression group $(\mathrm{P}=0.004)$. By contrast, high expression levels of AMPK were significantly associated with a lower survival rates compared with low expression levels of AMPK ( $\mathrm{P}=0.026$; Fig. 3). The associations between the combined expression of AMPK and TET2 
A

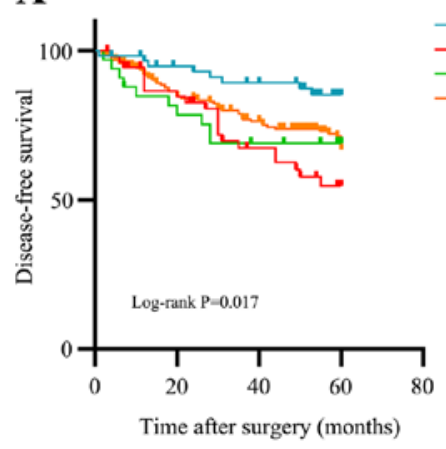

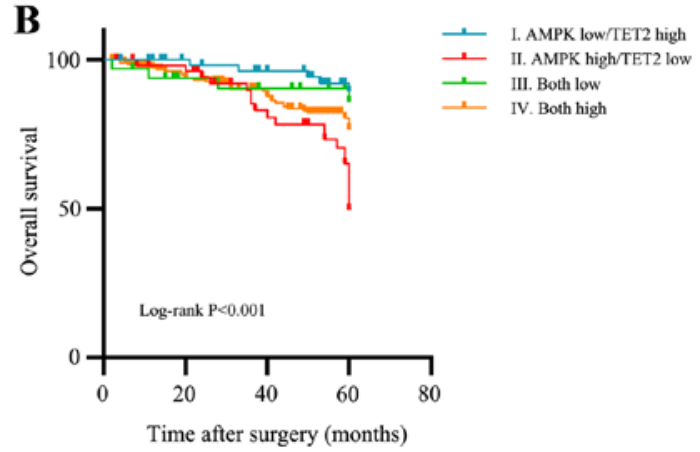

Figure 4. Kaplan-Meier survival curves of DFS and OS using combined AMPK and TET2 expression levels. (A) DFS and (B) OS analysis based on the combined expression status of AMPK and TET2. DFS, disease-free survival; OS, overall survival; AMPK, AMP-activated protein kinase; TET2, ten-eleven translocation 2 .

and the clinical outcome, including OS and tumor recurrence, were also investigated. The samples were divided into groups based on the expression levels of both AMPK and TET2. Kaplan-Meier curve analysis results demonstrated that the DFS and OS prognosis was poorer in the AMPK high/TET2 low expression group compared with that in the AMPK low/TET2 high group $(\mathrm{P}=0.017$ and $\mathrm{P}<0.001$, respectively, with Bonferroni correction; Fig. 4). The results of the multivariate analysis revealed that the AMPK high/TET2 low expression pattern was an independent prognostic factor for DFS and OS $(\mathrm{P}=0.013$ and $\mathrm{P}=0.018$, respectively; Tables IV and $\mathrm{V})$.

\section{Discussion}

The present study investigated the clinical relevance of AMPK and TET2 expression levels in a large cohort of patients with CRC. The results of the present study demonstrated that high expression levels of TET2, but not AMPK, predicted a favorable prognosis for patients with CRC, despite the significant correlation between AMPK and TET2 expression levels. The first group to establish a relationship between cellular metabolism and tumorigenesis was Warburg et al (17); their study demonstrated continued aerobic glycolysis of tumor cells despite oxygen-rich conditions. AMPK is an enzyme associated with cancer and cell metabolism $(18,19)$. A number of studies, including those in CRC, have studied the prognostic roles of AMPK; in the majority of cases, the expression levels of AMPK have been associated with a favorable prognosis (20-22). Based on preclinical data, these results indicate that AMPK generally serves a role as a tumor suppressor, regulates cell proliferation and induces apoptosis by upregulating p53 (23). In addition, AMPK-dependent activation of the tuberous sclerosis complex inhibits the mTOR pathway, further inhibiting cell proliferation and protein synthesis (12). By contrast, in the present study, the expression levels of AMPK were associated with lymphatic invasion and an advanced cancer stage, indicating a poor prognosis. These results suggested that AMPK may serve different roles depending on the tumor microenvironment.

In an in vivo study, Jang et al (24) reported that the development of glioma was associated with high levels of AMPK activation in the early tumor microenvironment. In addition, AMPK has been reported to serve a role in inducing tumor cell proliferation, and the deletion of oncogenic RAS and PTEN has been demonstrated to activate AMPK (18). The activation of AMPK has also been observed in non-stressful conditions, typically by hormones (25). Hormones such as leptin and interleukin- 6 are involved in the progress and development of certain solid tumors, such as prostate, colorectal and breast (26). In hypoxic tumor cells, inducible AMPK may also serve a pro-survival role analogous to that proposed for hypoxia-inducible factors during tumorigenesis (27). In clinical studies, tumor grade, prognosis and their association with high expression levels of AMPK or phosphorylated AMPK have been reported in various solid tumors, including colon, breast, ovarian, prostate and cervical cancer $(19,21,28)$. In addition, AMPK has been demonstrated to be involved in the invasion and migration of cancer cells through various other signaling pathways, and novel kinase family 1 , which are members of the AMPK family, serve an important role in cell migration and invasion by regulating the AKT/NF- $\kappa B$ signaling pathway $(29,30)$.

A recent study has demonstrated that AMPK is a key nutrient or energy sensor with high sensitivity for blood glucose levels, and that TET2 expression is upregulated by AMPK (15). In addition, AMPK serves an important role in protecting the stability of TET2 by phosphorylating TET2 S99 in high glucose conditions (15). In the present study, no statistical associations were identified between the expression levels of AMPK or TET2 and diabetes mellitus or high glucose levels. However, those results were obtained as single data points measured during the study; therefore, to overcome these limitations, further studies are required to measure blood glucose levels at various time points.

The results of the present study were consistent with those of previous studies suggesting that low expression levels of TET2 indicate a poor prognosis and demonstrating that methylation serves an important role in CRC $(31,32)$. The inactivation of TET 2 has been reported in $15 \%$ of hematopoietic malignancies as well as CRC; in addition, IDH1/2 gene mutations have also been identified in glioma, chondrosarcoma and thyroid carcinoma (33-35). DNA methylation occurs throughout the genome and is constantly maintained during the replication process (36). Although DNA methylation is a physiological process, a decrease in the levels of 5 -hmC can affect tumorigenesis (10). Various 
mechanisms exist to protect $\mathrm{CpG}$ island promoters from DNA methylation, such as the binding of TET1 and the exclusion of de novo DNA methyltransferases by trimethylation of histone $\mathrm{H} 3$ at lysine $4(37,38)$. In addition, $\mathrm{CpG}$ islands and promoters inhibit ectopic DNA methylation by the polycomb-associated F-box and leucine-rich repeat protein 10 (39). Therefore, DNA methylation is protected through various defensive mechanisms in addition to TET2, which is why it is necessary to conduct further studies on AMPK, as well as TET2.

The results of the present study demonstrated that although a significant correlation existed between the expression levels of AMPK and TET2, they were associated with conflicting prognoses. This result may suggest that TET2 increases in response to methylation as CRC progresses, and that the role of AMPK increases during tumor cell migration and invasion according to the metabolic needs of the tumor cells.

There were several limitations to the present study, including its retrospective nature and selection biases. In addition, inconsistent results may have been observed due to a lack of an established methodology for evaluating the expression of AMPK and TET2. Also, clinical in vivo and in vitro studies such as functional tests and prospective studies are needed to evaluate the AMPK/TET/5-hmC axis further. Although the association between diabetes mellitus and AMPK/TET2 expression, which was one of the hypotheses of the present study, was not determined, the results demonstrated that the levels of AMPK/TET2 expression may be a powerful prognostic predictor of diabetes-associated CRC. However, it is difficult to determine the relevance of AMPK/TET2 expression levels in diabetes mellitus based solely on the results of the present study.

In conclusion, the results of the present study demonstrated that TET2 expression was an independent factor for recurrence and survival of patients with CRC, and was a more significant predictor of prognosis compared with AMPK. In addition, the prognostic value of AMPK and TET2 levels combined was greater compared that of the expression levels of each protein alone. Further analyses are warranted to fully establish AMPK/TET2/5-hmC as a predictive biomarker or a therapeutic target for CRC.

\section{Acknowledgements}

The authors would like to thank Mr. Tae Wan Kim and Dr Son Myung Won at Soonchunhyang University Cheonan Hospital for their help. The abstract of the present study was presented at the 39th Congress of the European Society of Surgical Oncology, Oct 9-11 (29), 2019 in Rotterdam, The Netherlands, and published as abstract no. 477 in the European Journal of Surgical Oncology 46.2 (2020): e171.

\section{Funding}

This research was supported by the Soonchunhyang University Research Fund, the Korea Health Technology R\&D Project through the Korea Health Industry Development Institute and the Ministry of Health \& Welfare, Republic of Korea (grant no. HI17C0031).

\section{Availability of data and materials}

The datasets used and/or analyzed during the current study are available from the corresponding author on reasonable request.

\section{Authors' contributions}

DHK developed the project, collected and analyzed the data, and wrote the manuscript DJJ and TSA analyzed the data and edited the manuscript. HYL collected the data. HaJK and SBB collected the data and edited the manuscript. HyJK performed the tissue experiments. HYK designed the study and analyzed the data. MSL designed the study, performed statistical analysis and edited the manuscript. MJB designed the study and revised the manuscript. DHK, TSA and MJB confirm the authenticity of all the raw data. All authors read and approved the final manuscript.

\section{Ethics approval and consent to participate}

All participants provided written informed consent and agreed to scientific use of their data. The Institutional Review Board of the Soonchunhyang University Cheonan Hospital approved the present study (approval no. SCHCA 2019-08-018; Cheonan, South Korea).

\section{Patient consent for publication}

Not applicable.

\section{Competing interests}

The authors declare that they have no competing interests.

\section{References}

1. Bray F, Ferlay J, Soerjomataram I, Siegel RL, Torre LA and Jemal A: Global cancer statistics 2018: GLOBOCAN estimates of incidence and mortality worldwide for 36 cancers in 185 countries. CA Cancer J Clin 68: 394-424, 2018.

2. Jung KW, Won YJ, Hong S, Kong HJ and Lee ES: Prediction of cancer incidence and mortality in Korea, 2020. Cancer Res Treat 52: 351-358, 2020

3. Siegel RL, Miller KD and Jemal A: Cancer statistics, 2020. CA Cancer J Clin 70: 7-30, 2020.

4. Ogino S and Goel A: Molecular classification and correlates in colorectal cancer. J Mol Diagn 10: 13-27, 2008.

5. Li D: Recent advances in colorectal cancer screening. Chronic Dis Transl Med 4: 139-147, 2018.

6. Di Croce L, Raker VA, Corsaro M, Fazi F, Fanelli M, Faretta M, Fuks F, Lo Coco F, Kouzarides T, Nervi C, et al: Methyltransferase recruitment and DNA hypermethylation of target promoters by an oncogenic transcription factor. Science 295: 1079-1082, 2002.

7. Ko M, An J and Rao A: DNA methylation and hydroxymethylation in hematologic differentiation and transformation. Curr Opin Cell Biol 37: 91-101, 2015.

8. Jones PA: Functions of DNA methylation: Islands, start sites, gene bodies and beyond. Nat Rev Genet 13: 484-492, 2012.

9. Tahiliani M, Koh KP, Shen Y, Pastor WA, Bandukwala H, Brudno Y, Agarwal S, Iyer LM, Liu DR, Aravind L and Rao A: Conversion of 5-methylcytosine to 5-hydroxymethylcytosine in mammalian DNA by MLL partner TET1. Science 324: 930-935, 2009.

10. Jin SG, Jiang Y, Qiu R, Rauch TA, Wang Y, Schackert G, Krex D, Lu Q and Pfeifer GP: 5-Hydroxymethylcytosine is strongly depleted in human cancers but its levels do not correlate with IDH1 mutations. Cancer Res 71: 7360-7365, 2011. 
11. Haffner MC, Chaux A, Meeker AK, Esopi DM, Gerber J, Pellakuru LG, Toubaji A, Argani P, Iacobuzio-Donahue C, Nelson WG, et al: Global 5-hydroxymethylcytosine content is significantly reduced in tissue stem/progenitor cell compartments and in human cancers. Oncotarget 2: 627-637, 2011.

12. Wang W and Guan KL: AMP-activated protein kinase and cancer. Acta Physiol (Oxf) 196: 55-63, 2009.

13. Hardie DG: AMP-activated/SNF1 protein kinases: Conserved guardians of cellular energy. Nat Rev Mol Cell Biol 8: 774-785, 2007.

14. Marin TL, Gongol B, Zhang F, Martin M, Johnson DA, Xiao H, Wang Y, Subramaniam S, Chien S and Shyy JY: AMPK promotes mitochondrial biogenesis and function by phosphorylating the epigenetic factors DNMT1, RBBP7, and HAT1. Sci Signal 10: eaaf7478, 2017.

15. Wu D, Hu D, Chen H, Shi G, Fetahu IS, Wu F, Rabidou K, Fang R, Tan L, Xu S, et al: Glucose-regulated phosphorylation of TET 2 by AMPK reveals a pathway linking diabetes to cancer. Nature 559: 637-641, 2018.

16. Edge SB and Compton CC: The American Joint Committee on Cancer: The 7th edition of the AJCC cancer staging manual and the future of TNM. Ann Surg Oncol 17: 1471-1474, 2010.

17. Warburg $\mathrm{O}$, Wind $\mathrm{F}$ and Negelein E: The metabolism of tumors in the body. J Gen Physiol 8: 519-530, 1927.

18. Ríos M, Foretz M, Viollet B, Prieto A, Fraga M, Costoya JA and Señarís R: AMPK activation by oncogenesis is required to maintain cancer cell proliferation in astrocytic tumors. Cancer Res 73: 2628-2638, 2013

19. Park HU, Suy S, Danner M, Dailey V, Zhang Y, Li H, Hyduke DR, Collins BT, Gagnon G, Kallakury B, et al: AMP-activated protein kinase promotes human prostate cancer cell growth and survival. Mol Cancer Ther 8: 733-741, 2009.

20. Baba Y, Nosho K, Shima K, Meyerhardt JA, Chan AT, Engelman JA, Cantley LC, Loda M, Giovannucci E, Fuchs CS and Ogino S: Prognostic significance of AMP-activated protein kinase expression and modifying effect of MAPK3/1 in colorectal cancer. Br J Cancer 103: 1025-1033, 2010.

21. Buckendahl AC, Budczies J, Fiehn O, Darb-Esfahani S, Kind T, Noske A, Weichert W, Sehouli J, Braicu E, Dietel M and Denkert C: Prognostic impact of AMP-activated protein kinase expression in ovarian carcinoma: Correlation of protein expression and GC/TOF-MS-based metabolomics. Oncol Rep 25 1005-1012, 2011.

22. Tsavachidou-Fenner D, Tannir N, Tamboli P, Liu W, Petillo D, The B, Mills GB and Jonasch E: Gene and protein expression markers of response to combined antiangiogenic and epidermal growth factor targeted therapy in renal cell carcinoma. Ann Oncol 21: 1599-1606, 2010.

23. Okoshi R, Ozaki T, Yamamoto H, Ando K, Koida N, Ono S, Koda T, Kamijo T, Nakagawara A and Kizaki H: Activation of AMP-activated protein kinase induces p53-dependent apoptotic cell death in response to energetic stress. J Biol Chem 283 3979-3987, 2008.

24. Jang T, Calaoagan JM, Kwon E, Samuelsson S, Recht L and Laderoute KR: 5'-AMP-activated protein kinase activity is elevated early during primary brain tumor development in the rat. Int J Cancer 128: 2230-2239, 2011.
25. Kola B, Boscaro M, Rutter GA, Grossman AB and Korbonits M: Expanding role of AMPK in endocrinology. Trends Endocrinol Metab 17: 205-215, 2006

26. Mistry T, Digby JE, Desai KM and Randeva HS: Obesity and prostate cancer: A role for adipokines. Eur Urol 52: 46-53, 2007.

27. Rankin EB and Giaccia AJ: The role of hypoxia-inducible factors in tumorigenesis. Cell Death Differ 15: 678-685, 2008.

28. Hadad SM, Baker L, Quinlan PR, Robertson KE, Bray SE, Thomson G, Kellock D, Jordan LB, Purdie CA, Hardie DG, et al: Histological evaluation of AMPK signalling in primary breast cancer. BMC Cancer 9: 307, 2009.

29. Chen P, Li K, Liang Y, Li L and Zhu X: High NUAK1 expression correlates with poor prognosis and involved in NSCLC cells migration and invasion. Exp Lung Res 39: 9-17, 2013.

30. Suzuki A, Lu J, Kusakai G, Kishimoto A, Ogura T and Esumi H: ARK5 is a tumor invasion-associated factor downstream of Akt signaling. Mol Cell Biol 24: 3526-3535, 2004.

31. Yang H, Liu Y, Bai F, Zhang JY, Ma SH, Liu J, Xu ZD, Zhu HG, Ling ZQ, Ye D, et al: Tumor development is associated with decrease of TET gene expression and 5-methylcytosine hydroxylation. Oncogene 32: 663-669, 2013.

32. Zhang LY, Li PL, Wang TZ and Zhang XC: Prognostic values of 5-hmC, 5-mC and TET2 in epithelial ovarian cancer. Arch Gynecol Obstet 292: 891-897, 2015.

33. Hemerly JP, Bastos AU and Cerutti JM: Identification of several novel non-p.R132 IDH1 variants in thyroid carcinomas. Eur J Endocrinol 163: 747-755, 2010.

34. Pansuriya TC, van Eijk R, d'Adamo P, van Ruler MA, Kuijjer ML, Oosting J, Cleton-Jansen AM, van Oosterwijk JG, Verbeke SL, Meijer D, et al: Somatic mosaic IDH1 and IDH2 mutations are associated with enchondroma and spindle cell hemangioma in Ollier disease and Maffucci syndrome. Nat Genet 43: 1256-1261, 2011

35. Parsons DW, Jones S, Zhang X, Lin JC, Leary RJ, Angenendt P, Mankoo P, Carter H, Siu IM, Gallia GL, et al: An integrated genomic analysis of human glioblastoma multiforme. Science 321: 1807-1812, 2008.

36. Rasmussen KD and Helin K: Role of TET enzymes in DNA methylation, development, and cancer. Genes Dev 30: 733-750, 2016.

37. Guo X, Wang L, Li J, Ding Z, Xiao J, Yin X, He S, Shi P, Dong L, $\mathrm{Li} \mathrm{G}$, et al: Structural insight into autoinhibition and histone H3-induced activation of DNMT3A. Nature 517: 640-644, 2015.

38. Otani J, Nankumo T, Arita $K$, Inamoto $S$, Ariyoshi $M$ and Shirakawa M: Structural basis for recognition of H3K4 methylation status by the DNA methyltransferase $3 \mathrm{~A}$ ATRX-DNMT3-DNMT3L domain. EMBO Rep 10: 1235-1241, 2009.

39. Boulard M, Edwards JR and Bestor TH: FBXL10 protects Polycomb-bound genes from hypermethylation. Nat Genet 47: 479-485, 2015.

This work is licensed under a Creative Commons Attribution-NonCommercial-NoDerivatives 4.0 International (CC BY-NC-ND 4.0) License. 